\title{
THE ROLE OF ELECTRONIC INFORMATION RESOURCES IN ACADEMIC LIBRARIES OF KATSINA STATE, NIGERIA FOR NATIONAL DEVELOPMENT
}

\author{
Kabir Ibrahim Yar'adua CLN \\ College Library \\ Federal College of Education, Katsina. \\ Kabiribrahim433@gmail.com \\ Kabiribrahim97@yahoo.com
}

\section{Manuscript Info Abstract}

\section{Manuscript History}

Received: 06 November 2020

Final Accepted: 22 December 2020

Published: 10 January 2021

Online Published: February 2021

DOI :http:/ /dx.doi.org/10.35337/EIJLITR.2021.1204

Corresponding Author E-mail:

kabiribrahim433@gmail.com

(kabir Ibrahim Yar'adua Cln )

(C) Kabir Ibrahim Yar'adua CLN The Author. This is an open access article under the terms of the Creative Commons Attribution License 4.0, which allows use, distribution and reproduction in any medium, provided the original work is properly cited.

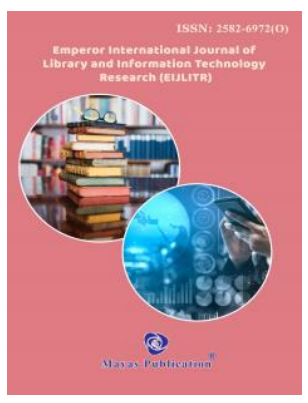

The appearance of data and correspondence Technology ICT has made an understood and unavoidable effect in pretty much every territory of scholarly libraries activity and administrations in Nigeria. All things considered, the libraries have gone through a quick changes prompting better approaches for data age and dispersal. The paper feature on ubiquity of e-assets and expanding needs for preparing for curators and library clients, to the compelling access and utilization of the assets. Library clients are getting it troublesome in getting access and powerful utilization of these assets. As a path forward, the paper suggested that scholarly libraries ought to give preparing to clients on the appropriate utilization of the assets and build up electronic assets place, sufficient ICT offices or more all continuous Internet network to get to $\mathrm{e}$ assets so as the materials ought to be of huge commitment to the advancement instructing, learning and exploration exercises in scholastic local area where the library serve.

\section{INTRODUCTION}

Academic libraries are set up in associations of higher sorting out some way to offer kinds of help to people from the educational neighborhood incorporates understudies, educators, researchers, etc They are set up and kept up by higher/tertiary foundations of learning like universities, polytechnics and schools of preparing. According to Ekere (2014), educational libraries insinuate such a library that is obvious from others, for instance, public, public and school libraries and others. This is because they give information materials in different designs to help showing learning and investigation. Of course Abubakar (2011) zeroed in on that academic libraries are at the front line of giving information organizations to their individual organizations which contains understudies, speakers and researchers to 
help their teaching, learning and investigation needs. Libraries in these foundations perform works direct related to the mission of each establishment they serve.

In this way, the explanation behind an academic library is to help the instructing, learning and investigation ventures of the establishment through mindfully picking, figuring out and getting adequate print and non-print information resources and making them open for use by understudies, workers and experts all things considered. (Idowu 2011) zeroed in on that academic libraries worldwide may fluctuate in size and intricacy, anyway they have one normal objective: to give information resources for energize training, learning, investigation and neighborhood set out upon by the parent foundation. It is fundamental for insightful libraries to serve the neighborhood critical information resources for meet their information needs.

"The ascent of electronic information resources has greatly changed information access and use and the creation and sharing of information similarly as defending in insightful libraries. Its organization implies a creating group of issues, tasks, cycles and practices related sincerely, appraisal, getting, affiliation, security and upkeep and give taught induction to electronic resources according to their grant terms". Anderson (2004) zeroed in on that organization of electronic resources can be seen as devices, which are used to gauge, orchestrate legitimate metadata, for instance, grant terms, merchant arrangements and use.

\section{Electronic Resources}

The progress in Information and Communication Technologies (ICT) has provoked emphasis on use of electronic resources in educational libraries. These headways, which appear in the libraries, have accomplished progressive changes in training, learning and investigation. Haugen (2005), believed that "the usage of advancement has provoked the globalization of academic libraries, which has energized the exchanging of information and contemplations across open and overall limits. It has changed the ordinary library into an automated, electronic, virtual and mechanized one". In the high level age, libraries are getting more electronic resources because of their obvious favorable circumstances, similar to straightforward induction to information and its meticulousness. With the introduction of ICT into library organizations, electronic resources, similar to CD-ROM data bases, PCs and other online resources, are used in teaching, learning and investigation purposes.

Electronic information resources subsequently, are overall the resources that appear in electronic design as opposed to the standard kind. They pass on information resources in a PC based way. By definition, electronic information resources or essentially electronic resources (e-resources) are information taken care of in electronic plan in PC or PC related workplaces (CD-ROM, streak drives, progressed libraries or the Internet). As demonstrated by Padma (2014), "an electronic resource requires PC access or any electronic thing that passes on a collection of data, be it text implying full substance bases, electronic journals, picture varieties, other media things and numerical, graphical or time based, as a monetarily available title that has been dispersed with an expect to be advanced". These may be passed on CD-ROM, on tape, by methods for Internet, and so on Electronic resources are a scrap of information set aside as electrical signals and is ordinarily found on a PC (Prakash 2015). The resources can be gotten to through a PC, unified PC or handheld phone. They have consistently become and remained resources in each higher establishment. Electronic resources support assessment and accept a free part to print library resources. These resources if available in a library expect an obvious part in urging permission to information by the customers in a straightforward and speedy manner.

Henceforth, electronic information resources, in certified sense, have become the spines of various educational associations around the planet, and along these lines, insightful library organization course of action is fundamentally developing. Electronic resources are including a basic piece of the overall composition. This has provoked the fast new development and universality of electronic resources. Dhanavandan, Mohammed and Esmail (2012) communicated that there are a couple of sorts of electronic resources which are open on the Internet. Critical ones that are making progress are electronic journals, computerized books, particular judgments, reports, licenses, full substance articles, trade reports and others. The different kinds of e-resources are computerized books, e-journals, informational indexes, 
CDs/DVDs, e-gathering methods, e-reports, e-creations, e-hypotheses, e-paper and Internet/destinations. These may be passed on CD-ROM/DVD, over the Internet, and so forth

Electronic information resources offer opportunities to get adequate writing in a secured and ideal plan viably. The sensational advancement of electronic information has wind up being more worth included nature and proficient for an individual. As demonstrated by Prakash (2015), electronic resources are a scrap of information set aside as electrical signals and is regularly found on a PC. They can be gotten to whether through a PC, unified PC or handheld phone. In like manner, electronic information has step by step become and remains a resource in each higher establishment. They support investigation and accept a free part to print library resources.

\section{National Development}

Public, as shown by Longman word reference of contemporary English, suggests a miracle that acknowledges a whole country. Public improvement in this manner can be portrayed as the overall new development or a total monetary, political similarly as severe movement of a country or country. This is best cultivated through progress of arrangement, which can be depicted as the country's variety of approaches illustrated by the public position.

Headway can similarly be viewed as the constraint of a nation to fabricate its static economy to a level where it can make and support a yearly extension in its Gross National Product (GNP). Headway isn't limited to just the route toward obtaining ventures, yet wraps such cycles as modernization, productivity, social and monetary equilibrium, present day specific expertise, improved foundations and mindsets similarly as regularly arranged technique mechanical gathering (Oghator and Okoobo 2000). Headway is essential and pivotal for the food and improvement of any country. This derives that headway isn't about a particular perspective anyway it is including, better still multi-dimensional depending upon the reason for struggle. Ahmed (2007) in like manner saw that improvement is stressed over the general up liftmen in the plan of good and convincing instructing and learning materials in a given human culture.

The plan of palatable and capable electronic resources in our academic foundations libraries will improve quick open new development, Researchers, speakers and understudies can agreeably approach, use, share overall composition and talk with the world force happening inside a particular locale.

\section{Challenges facing Electronic Information Resources Use in Academic Libraries}

Despite the way that electronic resources have a lot of preferences, there are a couple of deterrents and challenges to its incredible use. The choice of e-resources has made unfathomable piece of breathing space over printed resources in library organization and movement. Regardless, insightful libraries face different challenges as they hope to continue to offer the critical level of organizations to their customers. Igun, (2005) imagined that challenges looked by the libraries and information center in the establishment of electronic Information resources fuses getting of capacities to manage current e-instruments, metadata data for ordering e-resources, expertise in allowing e-journals and upkeep of URLs among others. Understudies used electronic resources for get insightful information and current care, and the huge limits looked by their inadequacy of PCs, defenseless web accessibility and nonappearance of movement capacities. Various troubles of electronic resources join the going with:

$>$ Preservation-Though the e-resources are engaging information to be made, controlled, scattered and arranged gracefully, saving induction to this information have an uncommon test. But in the event that, assurance of cutting edge information is viably taken, the information will get removed in light of changing development stage and media instability.

$>$ Nonappearance of master capacities Due to nonattendance of the board and concentrated capacities, the library specialists can't manage the e-resources. The master staffs are expected to constantly invigorate their own knowledge and capacity base to work in the present rapidly changing progressed environment.

$>$ Insufficient library store Most of the libraries have lacking resource for acquiring e-resources in this way the customers don't get their down and out information at the helpful time. Libraries are unsuspecting when acting alone in this environment and there is need for supportive purchasing through library consortia. 
> ICT structure In a modernized information organization system, establishment like programming, gear, web workplaces and other real equipment are expected to give more straightforward, speedier and broad induction to information. Subsequently, libraries in the high level age need to improve and upgrade current particular designing to oblige e-resources. Okiki and Ashiru(2011) zeroed in on that the significant issues experienced by customers in getting to electronic information resources is moderate web organization, ceaseless power outage and two or three PCs with web workplaces. The components that impede effective use of electronic resources are immense mass of unimportant information, the need to channel the results from search, download delay, failure to find information and lacking or nonappearance of search capacities. Ukpebor (2012), zeroed in on that there is a prerequisite for extra planning to build the standard capacities data base with a competency in electronic information resources use.

\section{CONCLUSION}

On the last note, doubtlessly electronic information resources is basic from now on by far most of the educational libraries have now move to cutting edge contraptions, accordingly we can't vanish without its usage. Compelling course of action of these materials in academic libraries needs a prevalent and steady organization of these resources to make it dependable use. In this manner, library computerization directors and the leading body of libraries should undoubtedly needs to walk more effort in the relationship of electronic information resources available in their libraries.

\section{Recommendations}

For convincing usage of electronic information resources in insightful libraries the going with proposition was made as follows:

$>$ There should be a level of capacity in the use of ICT among Students in tertiary establishments.

$>$ Academic libraries should give information organization system, establishment like programming, gear, web workplaces and other genuine equipment which will give easier, faster and sweeping induction to information.

$>$ Academic libraries in the modernized age need to improve and redesign current particular plan for electronic information resources.

$>$ Government should give adequate resources for the libraries to enable them gain and purchase in to their vendors.

$>$ Also plan of stay by generator should be open.

\section{REFERENCE}

1. Abubakar, B. M. (2011) Academic Libraries in the 21st Century. Library Philosophy and Practice.

2. Anderson, I. (2004) Electronic Resource Management: Report of the DLF electronic resource management initiative. Retrieved from http://www.diglib.org/pubs/dlf102/dlfermi0408appa.pdf.

3. Ahmed, H. (2007). Strategies for Accelerated Rural and Community Development at Local Government Level. The Nigerian Journal of Administrative Studies, 5(3): 64-77.

4. Ekere, F. \& Ekere, J. (2014). Contemporary Challenges facing Library and Information Science Professions in Nigeria: Global challenge and enhancement strategies. Proceeding from first International Conference of the Faculty of Education, University of Nigeria, Nsukka, held from 17th-21st June.

5. Dhanavandan, M. Esmal S. ansd Nagarajan, M. (2012) Use of Electronic Resources at Krishnasamy College of Engineering and Technology Library, Cuddalore Library Philosophy and Practice, Retrieved March 12, 2013, from http://www.unllib.unl.edu.

6. Huagen B. (2005) The Impact of Globalization on Law Libraries. Int. Journal Legal Inform. 33(3). Retrieve August 19, 2008 from http:/ / search.epnet.com/login.aspx

7. Idowu, A. O. (2011) Effective Library Services in the College. A Paper delivered at the 1st Library Workshop at Adeyemi College of Education, Ondo. 
8. Iwehabura S. (2009). The use and impact of electronic resources at the University of Lagos. Library Philosophy and Practice. Available. www.webpages.uidaho.edu/mbolin/egberonbe.html.(15 sept. 2009)

9. Oghator, E. \& Okoobo, R. (2000). Towards Sustainable Development in less Developed Countries: Foreign Assistance Revisited. The Nigerian Journal of Administrative Science, 5 (10): 201-208.

10. Okiki, O. C. and Ashiru H.(2011). Electronic information resources awareness, attitude and use by academic staff members of University of Lagos, Nigeria. Retrieved May 23, 2015, from

11. http://digitalcommons.unl.edu/lipphiprac/828

12. Padma. P. et al.(2014). Awareness and Use of Electronic Resources by the Engineering e library research journal. 2(10).

13. Prakash, T. (2015). Use of Electronic Information Resources by Research Scholars of Kurukshetra University. The Electronic Library Journal. 28(4).

14. Ukpebor, C.O. (2012). Availability and use of electronic resources in African

15. universities: The Nigerian perspective. PNLA Quarterly, 76(3) (Spring 2012) 190-

16. 199. Retrieved March 1, 2015, from www.pnla.org 